\title{
Challenges and Coping Strategies in Achieving Physically Active Habits: The Case of Bachelor of Physical Education Students
}

\author{
Jay P. Mabini ${ }^{1}$, Jumhejell Louise B. Reyes ${ }^{2}$, Geraldine B. Aras ${ }^{3}$, \\ Ramil J. Homeres ${ }^{4}$, \\ ${ }^{1}$ Leyte Normal University, P. Paterno St., Tacloban City, 6500, Philippines \\ (jay.mabini@lnu.edu.ph) \\ ${ }^{2}$ Leyte Normal University, P. Paterno St., Tacloban City, 6500, Philippines \\ (1801776@Inu.edu.ph) \\ ${ }^{3}$ Leyte Normal University, P. Paterno St., Tacloban City, 6500, Philippines \\ (1801723@Inu.edu.ph) \\ ${ }^{4}$ Leyte Normal University, P. Paterno St., Tacloban City, 6500, Philippines \\ (1801219@Inu.edu.ph)
}

\begin{abstract}
Insufficient physical activity increases several different health hazards around the world. College students are recorded as one of the most physically inactive individuals because they face challenges that hinder them from practicing physically active habits. This study investigates the challenges and coping strategies of Physical Education students in achieving physically active habits. This study followed a qualitative case study design to provide a detailed and comprehensive analysis of the bounded phenomenon provided by the physical education students. A semi-structured interview was employed to draw pertinent data relative to the study and was treated qualitatively using thematic analysis. The results of the study pointed out the emerging challenges faced by physical education students in achieving physically active habits. Consequently, lack of selfmotivation, difficulty in time management, academic demands, and school responsibilities have been the core justification for their physical inactivity. Thus, the findings suggest that self-discipline, effective time management, and goal setting had been the coping strategies used by physical education students in achieving physically active habits. These results provide insights to students, teachers, parents, and future researchers as to how they can contribute to levering the healthy lifestyle of the students. This paper makes a unique contribution to the existing literature on the challenges encountered and coping strategies used by college students in achieving physically active habits.
\end{abstract}

Key Words: Challenges \& Coping Strategies; Physically Active Habits; Case Study

\section{Introduction}

According to Lees \& Booth (2005), physical inactivity causes 334,144 deaths in the United States per year and 2 million casualties throughout the world. Physical inactivity is responsible for one out of every ten fatalities worldwide, ranking with the dangers of smoking and obesity (Lee et al.,2012). The findings also suggest that public health specialists are treating this as a pandemic (Lee et al., 2012). SeDS or Sedentary Death Syndrome is a growing range of health disorders caused by insufficient physical activity, resulting in early death and disability (Lees \& Booth 2005). It is believed that 60 percent of all Americans will be at risk in the next ten years. In the United States, 
SeDS will cause about 2.5 million premature fatalities, which significantly results in higher than the total average amount of deaths caused by alcohol, weapons, motor vehicles, illegal drug use, and sexual activity combined. According to Knight (2012), SeDS is the second most important public health threat. Inadequate physical exercise has been known as the fourth biggest cause of death, responsible for over 3.2 million premature deaths worldwide (Rocha, 2015). Aside from the overall health advantages of regular basis exercise, it should also be kept in mind that physical fitness lowers the chance of early death from coronary diseases, diabetes, and other diseases. Hypertension, obesity, cancer, depression are only a few examples. (Warburton et al., 2006). Despite the widespread acceptance of active habits as an important part of leading a healthy living and for the growth and development of teenagers, a large proportion of children fail to meet the government's daily physical activity guidelines (Sari, 2009). Long-term sickness vulnerability begins in childhood and continues throughout life, therefore promoting health and wellness must start in the early years to continue throughout one's life (Warburton et al., 2006). The benefits of school-based fitness programs for kids' health, learning, and social abilities have been demonstrated, and a healthy lifestyle has been promoted through these programs (Veugelers, 2005). Moreover, lowering worldwide physical inactivity rates by just $10 \%$ to $20 \%$ might save between 500,000 and 1.3 million lives each year, as well as contribute at least a year to global longevity (Lee et al., 2012).

Even before the COVID-19 pandemic, university students in the Philippines already have a busy and demanding schedule in their academic activities. According to a recent survey on global trends in physical inactivity, approximately 40 percent of Filipinos were physically inactive. Guthold et al. (2008) discovered that 30 percent of Filipino men and 50 percent of Filipino women were not physically active enough. Filipino teenagers were in second place as the world's least physically active, nearly hitting out first by a hairline. The Philippines recorded a prevalence of 93.4 percent physical inactivity, whereas South Korea earned a score of 94.2 percent (Buctot et al., 2020). Subsequently, most adolescents do not meet physical activity standards, compromising their current and future health. Physical Education students are always prone to physical activities like dancing, sports activities, aerobic exercises, and physical fitness training compared to other courses. However, challenges might hinder them from achieving physically active habits despite this tremendous training, especially during this pandemic. COVID-19 restrictions such as the suspension of schools and parks and the discontinuation of sports and activity classes may prohibit the physical education students from meeting prescribed amounts of physical activity. There has been less research about the challenges and coping strategies that physical education students face to achieve physically active habits. There have been few studies in the Philippines on physical exercise and fitness levels among college students. Thus, this research will provide evidence of the physical education students' challenges and coping strategies faced and utilized in achieving physically active habits.

As a result, this research will attempt to fill in the gaps as to how these challenges faced by physical education students may affect aspects of their lives, such as academic performance. Still, it will also attempt to identify the coping strategies they employ to develop physically active habits. In this scenario, the research will help close a gap in the literature while also contributing to the development of new knowledge.

\subsection{Research Problem}

The study conducted by the researchers about the challenges that physical education students face in achieving physically active habits focuses on the contributing barriers that augment their physical inactivity and the mechanisms that help them overcome these challenges. The following questions governed the conduct of the study:

- What are the challenges of Bachelor of Physical Education students in achieving physically active habits? 
- How do Bachelor of Physical Education students cope with the challenges they face in achieving physically active habits?

\subsection{Theoretical Framework}

This research is mainly anchored on the Health Belief Model (HBM) by social psychologists Strecher and Rosenstock (1997). The HBM (1997) is a theory that can be used to drive actions in health promotion and preventing illness. This theory believes that modifying factors and individual behavior advantages reduces perceived dangers to health-related behaviors. Health behaviors are impeded by perceived barriers - more minor barriers aid health behavior change. It is one of the best used models for studying health behaviors, and it is used to explain and predict individual behavior changes.

University students are more vulnerable to adopting inadequate coping behaviors such as alcohol consumption and high caloric food intake. Furthermore, college students have been shown to have a lack of physical activity and sleep problems. Unhealthy lifestyle choices among university students may result in seven different diseases later in life. Thus, throughout their undergraduate years, they must maintain a healthy lifestyle. The Health Belief Model (HBM) is a framework for inspiring people to perform beneficial health actions. The desire to avoid a poor health consequence serves as the primary motivator.

\subsection{Scope and Limitation}

This study is an investigation to gather data from the selected participants regarding their challenges and coping strategies in achieving physical actives habits. The results only represent the chosen case which was conducted in one of the universities in Eastern Visayas, Philippines. Its results may not apply to other individuals. Thus, its results may only be unique and distinct to their experiences.

\section{Methodology}

This is qualitative research employing a single case study research design. The distinctions between phenomena and context are obscured while using the case study research technique (Yin, 2003). The research was conducted in one of the state universities in Eastern Visayas. This locale is the most accessible university that offers a Bachelor of Physical Education. Due to the pandemic, researchers could not conduct a face-to-face interview. Hence, the study was conducted virtually. The researchers utilized purposive sampling in this study where twelve participants have been selected based on the following criteria: 1) he/she must be a physical education student at the selected university; 2) must be a 1st year to third-year student; 3) must not be an irregular student; and 4) should be willing to participate in the study that was conducted. The researchers employed a semi-structured interview to draw pertinent data relative to the study which was then treated using thematic analysis. Six steps (6) were followed in the analysis (Clarke \& Braun, 2013): 1) Familiarize yourself with your data; 2) Assign preliminary codes to your data to describe the content; 3) Search for patterns or themes in your codes across the different interviews; 4) Review themes; 5) Define and name themes; and 6) Produce the report. To secure the trustworthiness of the data, the researchers utilized triangulation with the parents/guardians and friends for additional data.

\section{Results and Discussion}

The student participants have shared their varied responses regarding their challenges and coping strategies in achieving physically active habits. 


\subsection{Challenges in Achieving Physically Active Habits}

Lack of self-motivation. According to Rhodes and Horne (2013), motivation is crucial in children's and adolescents' habit development. However, a lack of self-motivation is seen as one of the challenges in achieving physically active habits among BPED students. The pandemic has adversely heightened the lack of self-motivation among these students in achieving physically active habits or just doing simple physical activities in their house.

Significant Statement 1. "Before the pandemic started, I am having my regular exercise like jogging and having some walk outside. But when the pandemic started, I was not able to perform those exercises. I always feel lazy. It feels like I don't want to work on my assigned task." (P4)

Significant Statement 2. "First of all, mostly I feel lazy, I choose to go to bed instead of going for a jogging." (P6)

Difficulty in Time Management. Whatever one does or plans to do, time is essential. According to the findings of Eichorn and Bruner (2018), teaching children how to balance their personal lives, academics, and work will give them more time to exercise, which will improve their general well-being and quite as well for their entire lives. People may be interested in physical activity, but they have limited time due to the constraints of their jobs. This is a true challenge to the participants of the study. Time management is difficult among different things such as personal, academic, peers, and responsibilities at home.

Significant Statement 1. "I also help at home since we are in an online-based instruction, and we are only at home. I do still have my responsibilities. So, I am a student and a daughter. Most of the time I do not engage in physical activities anymore unlike before during face-to-face classes we get to engage." (P3)

Significant Statement2. "I am the president of our class, and I also have responsibilities for the BPED organization as the leader of the BPED Tech team. That is why I am unable to engage in my usual physical activities." (P2)

Academic demands and Household Responsibilities. According to Eichorn et al. (2018), college students are inhibited from exercising due to other factors. The participants recollected that the demand in academic works interferes with engaging them in different physical exercises. Because students are bombarded with modules, they tend to focus more on accomplishing the tasks given in the modules rather than doing physical activities.

Significant Statement 1. "Although schoolwork is my priority as a student, it interferes with my daily routines and prevents me from engaging in much physical exercise because we are constantly bombarded with modules." (P2)

Apart from this, participants also find it challenging to develop their talents and skills, and at the same time, they tend to have muscular problems because most of the tasks given to them are written form. Hence, there is an unequal opportunity for the participants to do physical training.

Significant Statement 2. "I am having difficulty on how to develop my skills and improve my other skills because in today's setup, we are just learning online and most of the activities are written so it is quite hard for us to develop our skills and mold our talents, and I also feel like I'm having some muscle cramps whenever I am doing something that I am not used to. ”(P5) 


\subsection{Coping Strategies in Achieving Physically Active Habits}

This highlights each of the participants' coping strategies in achieving physically active habits. The emergent sub-themes are self-discipline, effective time management, and goal setting.

Self-Discipline. According to Baumeister et al. (2007), self-discipline is frequently characterized as a laborious task requiring resources and an "active self." In the traditional "strength model of self-control," self-discipline is depicted as drawing from a self-regulatory resource that is prone to depletion and eventual self-control failure. Hence, the participants' discipline has been mentioned as the primary coping strategies that they use to achieve physically active habits. Selfdiscipline comes from different forms and activities. Due to the demand for written activities in their field, some participants see the need to eat healthy foods rather than do physical activities to maintain a healthy lifestyle. Hence, participants tend to discipline themselves through the food they intake.

Significant Statement 1. "Having an organized mindset, it very useful to achieve these habits. Because it is up to us make an action to do what is best to achieve things, we want to. " (P11)

Significant Statement 2. "Self-discipline will always be the best coping strategy. Like eating healthy foods such as vegetables. And make sure to balance everything and avoid eating junk foods. " (P7)

Effective Time Management. By efficiently and adequately controlling time, you can boost your chances of success (Khan et al., 2016). Time management is one of the coping strategies that the students usually utilize to overcome their challenges in achieving physically active habits. Students make time to energize their bodies by balancing their time doing their school works and doing simple physical exercises.

Significant Statement 1. "I usually make time for my body to be energized like doing exercises or dancing making TikTok videos in that way it can energize my nerves and achieve physically fit body." (P11).

Significant Statement 2. "I make sure to always have a spare time for exercise and do some physical activities. I finish my school works on time so that I would be able to have enough time for some recreational activities." (P6)

Goal Setting. Students must set academic and personal goals and choose suitable physical exercise, as habit formation requires regular repetition (Verplanken \& Melkevik, 2008). Participants suggested that students should practice setting goals. As per the participants, setting goals will help them overcome the challenges in achieving physically active habits. In addition, students see setting goals to achieve a good mindset and body. This will also definitely help students manage tasks effectively. Aside from this, setting goals is also perceived as a solution to having an organized mindset. This will help the students to know things that need to be considered.

Significant Statement 1. "Just think what's the best for you like setting goals because It'll help you overcome those challenges and work hard and be responsible." (P9)

\subsection{Triangulation}

To ensure the trustworthiness of the data gathered, a triangulation approach was employed in this study. The participant's guardian, parents, and friends shared that their child's/friends' challenges and coping mechanisms enabled them to achieve physically active habits. The responses 
helped the researchers in ensuring the quality and trustworthiness of the study. The following accounts are the significant statements supporting the claims of the participants:

Significant Statement 1. "My child is lazy all the time, and they prefer to stay in their bedroom and sleep than go for a walk or jogging. I think they are always destructed and demotivated to have their exercise." (P6 Parent)

Significant Statement 2. "I don't know what is happening to them, and they have changed their routine since the pandemic started. Before, they were having regular exercises like walking and jogging. But when the pandemic started, they were not able to go outside and have some walk. It looks like they always feel demotivated, and they don't even work on their task." (P4 Parent)

Significant Statement 3. "My child is always busy with school works since he is a leader of a certain organization in their school. I always find him busy attending to his school activities and using gadgets such as laptops and cellphone, and he is also attending online classes making it hard for him to have spare time for his exercise." (P2 Parent)

\section{Conclusions}

Individuals who make regular physical activity a habit can reap health and well-being benefits for the rest of their lives. Physical fitness patterns throughout childhood to maturity are major determinants of an adult's physical fitness behaviors. As a result, the youths need to develop healthy habits at an early age. The lack of self-motivation, difficulty in time management, and academic demands, and household responsibilities during the pandemic are the emerging challenges that Bachelor of Physical Education (BPED) students face in achieving physically active habits. Since almost all students are in the new learning setup, they are more likely to be physically inactive. Hence, most college students, not only the BPED students, are experiencing these kinds of challenges, adversely affecting them, such as having health problems and mental issues. Thus, these challenges should be averted so that physical education students and other college students can perform well physically, mentally, and in turn, will help improve their academic standing.

To be able to surpass these challenges, the participants of the study came up with personal coping strategies in achieving physically active habits which have veered them away from a sedentary lifestyle. These are self-discipline, time management, and effective goal setting. These propositions from the participants should be utilized not just by physical education students but likewise in different programs to form physically active habits that will help improve their health. This awareness will aid in the development of high-quality physical education programs, instructional strategies, and teaching pedagogies to overcome these obstacles in the present and future.

\section{Recommendations}

Physical Education students should be able to begin by appreciating the importance of doing physically active habits in their emotional and physical health. Promote the development of time management skills aimed at ensuring that enough time is set aside for the physical activity. Teaching youths how to balance their personal lives, school, and work will free up more time for them to engage in physical activity, which will benefit their general health. Teachers should foster activities that will help boost students' motivation to make physically active habits. In addition, teachers must educate people on the benefits of exercise to their bodies and overall health. Moreover, teachers must administer a wide range of teaching approaches to create a meaningful and active learning experience to cater to student needs. Parents have a significant role in their children's habit formation. They should support their children in building their physical habits by 
fostering discipline in the customary practices of their children. In addition, non-physical education students should be able to participate in similar studies to observe the differing variables in specific cases.

\section{References}

Baumeister, R. F., Vohs, K., \& Tice, D. (2007). The strength model of self-control. Psychol. Sci. 16(3), 351-355. doi:.1111/j.1467-8721.2007.00534.x

Buctot, D. B., Kim, N., \& Kim, J. J. (2020). Factors associated with smartphone addiction prevalence and its predictive capacity for health-related quality of life among Filipino adolescents. Children and Youth Services Review, 110, 104758.

Clarke, V., \& Braun, V. (2013). Teaching thematic analysis: Overcoming challenges and developing strategies for effective learning. The psychologist, 26(2).

Eichorn, L., Bruner, K., Short, T., \& Abraham, S. P. (2018). Factors that affect exercise habits of college students. Journal of Education and Development, 2(1), 20.

Guthold, R., Ono, T., Strong, K. L., Chatterji, S., \& Morabia, A. (2008). Worldwide variability in physical inactivity: a 51 country survey. American journal of preventive medicine, 34(6), 486-494.

Khan, H. M. A., Farooqi, M. T. K., Khalil, A., \& Faisal, I. (2016). Exploring Relationship of Time Management with Teachers' Performance. Bulletin of Education and Research, 38(2), 249-263.

Knight, J.A. (2012). Physical inactivity: Associated Diseases and Disorders. 1(2), 1-5. https://doi.org/10.1177/0146167201277111

Lee, I. M., Shiroma, E. J., Lobelo, F., Puska, P., Blair, S. N., Katzmarzyk, P. T., \& Lancet Physical Activity Series Working Group. (2012). Effect of physical inactivity on major non-communicable diseases worldwide: an analysis of burden of disease and life expectancy. The lancet, 380(9838), 219-229.

Lees, S., Booth, F. (2005). Physical Inactivity is a Disease, 95(1), 73-79. https://doi.org/10.1139/h04-039

Rhodes, R. E., \& Horne, L. (2013). Deepening the measurement of motivation in the physical activity domain: Introducing behavioural resolve. Psychology of Sport and Exercise, 14(4), 455-460.

Rocha E. (2015) Physical Inactivity: Preventable Risk Factor of Cardiovascular Disease. In: Andrade J., Pinto F., Arnett D. (eds) Prevention of Cardiovascular Diseases. Springer, Cham. 6(2), 123-135. https://doi.org/10.1007/978-3-31922357-5_6

Sari, N. (2009). Physical inactivity and its impact on healthcare utilization. Health Economics, 18(8), 885-901.

Strecher, V. J., \& Rosenstock, I. M. (1997). The health belief model. Cambridge handbook of psychology, health and medicine, 113, 117.

Warburton, D. E., Haykowsky, M. J., Quinney, H. A., Blackmore, D., Teo, K. K., Taylor, D. A., ... \& Humen, D. P. (2004). Blood volume expansion and cardiorespiratory function: effects of training modality. Medicine and science in sports and exercise, 36(6), 991-1000.

Verplanken, B., \& Melkevik, O. (2008). Predicting habit: The case of physical exercise. Psychology of sport and exercise, 9(1), 15-26.

Veugelers, P. (2005). Effectiveness of school programs in preventing childhood obesity: A Multilevel Comparison. 95(3), 431-435. https://doi.org/10.2105/AJPH.2004.045898

Yin, R. K. (2003). Designing case studies. Qualitative Research Methods, 5, 359-386. 